\title{
MARJORIE ROUSSEAU-MINIER, Des Filles sans Joie. Le roman de la prostituée dans la seconde moitié du XIX siècle
}

\section{Maria Emanuela Raffi}

\section{OpenEdition}

\section{Journals}

Edizione digitale

URL: http://journals.openedition.org/studifrancesi/16607

DOI: 10.4000/studifrancesi. 16607

ISSN: 2421-5856

\section{Editore}

Rosenberg \& Sellier

\section{Edizione cartacea}

Data di pubblicazione: 1 juillet 2019

Paginazione: 184

ISSN: 0039-2944

Notizia bibliografica digitale

Maria Emanuela Raffi, «MARJoRIE rousseau-MinIER, Des Filles sans Joie. Le roman de la prostituée dans la seconde moitié du xIx siècle», Studi Francesi [Online], 187 (LXIII | I) | 2019, online dal 01 juillet 2019, consultato il 24 janvier 2021. URL: http://journals.openedition.org/studifrancesi/16607 ; DOI: https:// doi.org/10.4000/studifrancesi.16607

Questo documento è stato generato automaticamente il 24 janvier 2021.

\section{(c) (i) $(9)$}

Studi Francesi è distribuita con Licenza Creative Commons Attribuzione - Non commerciale - Non opere derivate 4.0 Internazionale. 


\title{
MARJORIE ROUSSEAU-MINIER, Des Filles sans Joie. Le roman de la prostituée dans la seconde moitié du XIX siècle
}

\author{
Maria Emanuela Raffi
}

\section{NOTIZIA}

MARJORIE ROUSSEAU-MINIER, Des Filles sans Joie. Le roman de la prostituée dans la seconde moitié du XIX siècle, Genève, Droz, 2018, 490 pp.

1 In un'introduzione tematica e bibliografica, l'autrice definisce il campo del suo intervento critico, i romanzi pubblicati fra il 1865 e il 1885, periodo in cui si fa più forte in tutta Europa la regolamentazione della prostituzione e in cui la letteratura, con il naturalismo, diventa più attenta al fenomeno, anzitutto con le opere dei Goncourt, di Huysmans e di Zola. Tenendo sempre aperto un orizzonte europeo, il saggio di Rousseau-Minier parte dalla concezione della donna nella seconda metà dell'Ottocento, fondata sulla sua debolezza fisica («femme-enfant») ma anche sulla sua istintività naturale, di cui la prostituta è una sorta di «exemple hyperbolique». Creatura instabile, la donna appare all'epoca come eminentemente «sensible», preda del sentimento amoroso, ma anche religioso, e dell'immaginazione che talvolta la trascina verso crisi di follia, inscrivendosi così in una "altérité inquiétante aux yeux des hommes du $\mathrm{xIX}^{\mathrm{e}}$ siècle». Tale alterità trova tuttavia la sua massima espressione nella sessualità, di cui la prostituta è in letteratura la rappresentazione più erotizzata, quella che fa emergere l'animalità maschile e al tempo stesso la paura della sessualità femminile, presentandosi così come il rovesciamento della donna ideale fortemente incarnata nell'Ottocento dalla Vergine Maria, vergine e madre.

2 Segue un'analisi dell'aspetto sociale della prostituzione, delle sue origini e della regolamentazione che la caratterizza nella seconda metà dell'Ottocento in cui si collocano molti dibattiti sul tema, esaminati a partire da tre capitali europee: Paris, 
Madrid e San Pietroburgo. Nel parallelo ambito della fiction, l'A. indica, intorno al 1870, la nascita di un nuovo genere narrativo: il «roman de fille», ou «roman de la prostituée», in contrapposizione al feuilleton a lieto fine matrimoniale di derivazione romantica. Attorno alla protagonista principale, la prostituta, la cui vita "precedente" viene spesso narrata attraverso l'analessi, il «roman de fille» si organizza in modo quasi fisso con la presenza di alcuni elementi costanti: «l'univers fictionnel du bordel», il passaggio da un tipo di prostituzione all'altro, l'ipotesi (illusoria) di redenzione della protagonista, il percorso inesorabile verso la morte. I grandi romanzi di riferimento sono naturalmente Nana di Zola, La Fille Elisa e Marthe dei Goncourt, i romanzi di López Bago e Pérez Galdós per la Spagna e, con qualche distinguo, Crime et châtiment di Dostoïevski per la Russia; ma attorno a questi, l'A. indica tutta una serie di riferimenti "minori" che danno l'immagine della variegata produzione dell'epoca.

Nella serrata analisi psicologico-sociale del fenomeno letterario, Rousseau-Minier lega l'emergere di un'eroina singolare come la prostituta a una serie di «bouleversements socio-économiques [...], parmi lesquels l'affirmation du capitalisme, la mise en place des débuts d'une société de consommation, et surtout l'émergence d'un nouveau modèle à la fois social et politique, la démocratie». Affermazioni impegnative, che l'A. illustra nella terza parte del volume in cui la prostituta è presentata come «marchandise convoitée pour son inutilité même, incarnation du luxe et du superflu», trofeo borghese dal punto di vista economico; in quanto ragazza del popolo essa rappresenta invece, in opposizione alla cortigiana fautrice dei fasti del Secondo Impero, l'ascesa e la rivincita del proletariato. Sono particolarmente Nana di Zola e La desheredada di Galdós a illustrare con maggiore evidenza i dati storico-socio-politici che accompagnano nei rispettivi paesi la figura della protagonista, mentre in tutti $\mathrm{i}$ «romans de fille» l'A. riconosce il problematico rapporto con l'Altro e in particolare con l'altro sesso, nonché il difficile rapporto con sé stessi che li collegano all'inquieta sensibilità dell'epoca. $\mathrm{E}$ anche al sentimento della morte, onnipresente in questo tipo di narrazione.

Definita come «figure du manque», la prostituta diventa il luogo delle possibili identificazioni: dell'artista anzitutto, che vi riconosce il proprio «équilibre précaire entre facticité et authenticité» - particolarmente in La Fille Elisa - e la marginalità sociale della propria funzione, nonché la mercificazione dell'opera d'arte. All'inverso, tuttavia, l'A. riconosce nella «dépossession de soi» anche una forza di resistenza e di affermazione contro la frammentazione che minaccia sia l'artista che la prostituta, eroina "paradoxal[e] et mélancolique», portatrice di una forte valenza simbolica che la porta fino alla mitizzazione, sia pure in negativo: «Si Nana se construit [...] en héroïne épique du Second Empire, c'est cependant par une inversion du rôle civilisateur attendu, en présidant non à la fondation de cette société, mais à sa destruction». 0 a un silenzioso e spirituale ripiegamento su di sé; in ogni caso alla contestazione della struttura e dell'estetica del romanzo romantico. 